\section{THE AMERICAN JOURNAL OF}

\section{PSYCHIATRY}

\section{Contents}

\section{March 2014, Volume 171}

\section{Editorials}

249 Alternative intensive therapy for PTSD Marylene Cloitre

252 A primate model of the effects of childhood antidepressant treatment

David A. Brent, Judy Cameron, and David A. Lewis

256 Treatment of psychosis and risk assessment for violence

Matthew M. Large

259 Increasing treatment engagement for persons with serious mental illness using personal health records John C. Fortney and Richard R. Owen

\section{Commentary}

262 A word to the wise about ketamine Alan F. Schatzberg

\section{Treatment in psychiatry}

265 Behavioral and psychiatric symptoms in prion disease Andrew Thompson, Angus Mackay, Peter Rudge, Ana Lukic, Marie-Claire Porter, Jessica Lowe, John Collinge, and Simon Mead

\section{Images in psychiatry}

275 When affective disorders were considered to emanate from the heart: the Ebers Papyrus Rami Bou Khatil and Sami Richa

\section{Reviews and overviews}

276 Emotion dysregulation in attention deficit hyperactivity disorder

Philip Shaw, Argyris Stringaris, Joel Nigg, and Ellen Leibenluft

\section{New research - articles}

294 A randomized controlled trial of 7-day intensive and standard weekly cognitive therapy for PTSD and emotion-focused supportive therapy Anke Ehters, Ann Hackmann, Nick Grey, Jennifer Wild Sheena Liness, Idit Albert, Alicia Deale, Richard Stott, and David M. Clark

305 Results of a multicenter randomized controlled trial of the clinical effectiveness of schema therapy for personality disorders

Lotte L. M. Bamelis, Silvia M. A. A. Evers, Philip Spinhoven, and Arnoud Arntz

323 Fluoxetine administered to juvenile monkeys: effects on the serotonin transporter and behavior Stal Saurav Shrestha, Eric E. Nelson, Jeih-San Liow, Robert Gladding, Chul Hyoung Lyoo, Pam L. Noble, Cheryl Morse, loline D. Henter, Jeremy Kruger, Bo Zhang, Stephen J. Suomi, Per Svenningsson, Victor W. Pike, James T. Winslow, Ellen Leibenluft, Danie! S. Pine, and Robert 8 . Innis

332 Association of violence with emergence of persecutory delusions in untreated schizophrenia Robert Keers, Simone Ullrich, Bianca L. Destavola, and Jeremy $W$. Coid

340 Multicenter voxel-based morphometry mega-analysis of structural brain scans in obsessive-compulsive disorder

Stella J. de Wit, Pino Alonso, Lizanne Schweren, David Mataix-Cols, Christine Lochner, José M. Menchón, Dan J. Stein, Jean-Paul Fouche, Carles Soriano-Mas, Joao R. Sato, Marcelo Q. Hoexter, Damiaan Denys, Takashi Nakamae, Seiji Nishida, Jun Soo Kwon, Joon Hwan Jang, Geraldo F. Busatto, Narcis Cardoner, Danielle C. Cath, Kenji Fukui, Wi Hoon Jung, Sung Nyun Kim, Euripides C. Miguel, Jin Narumoto, Mary L. Phillips, JesuS Pujol, Peter L. Remijnse, Yuki Sakal, Na Young Shin, Kei Yamada, Dick J. Veltman, and Odile A. van den Heuveł

350 Revisiting schizophrenia linkage data in the NIMH repository: reanalysis of regularized data across multiple studies

Veronica J. Vieland, Kimberly A. Walters, Thomas Lehner, Marco Azaro, Kathleen Tobin, Yungui Huang, and Linda M. Brzustowicz

360 Randomized trial of an electronic personal health record for patients with serious mental illnesses Benjamin G. Druss, Xu Ji, Gretl Glick, and Silke A. von Esenwien 